\title{
Are we any clearer on the blood pressure targets?
}

Singapore Med J 2014; 55(10): 553 doi: 10.11622/smedj.2014143

Dear Sir,

I refer to the article "Doctor, do I really need treatment for my blood pressure?" by How and Quah. ${ }^{(1)}$ The is a timely article that highlights some of the recommendations from the high blood pressure management guideline by the Eighth Joint National Committee (JNC 8), (2) which is an update of the JNC 7 guideline. The JNC 8 guideline on hypertension management is long awaited and way overdue (published ten years after the JNC 7 recommendations). The European Society of Hypertension (ESH) and European Society of Cardiology (ESC) have beaten the committee to it, releasing their guideline in July 2013 in the Journal of Hypertension. (3)

While the JNC 8 guideline focuses on a few randomised controlled trials, the ESH/ESC 2013 guideline also considers some observational studies "of appropriate scientific caliber". ${ }^{(3)}$ While both guidelines agree that, generally, for most patients aged > 18 years, the target blood pressure should be below 140/90 $\mathrm{mmHg}$, they differ in three areas (summarised in Table I):

1. The cutoff age to accept a less stringent target of < 150/90 mmHg: JNC 8 recommends $>60$ years, while ESH/ESC 2013 recommends $\geq 80$ years.

2. For patients with diabetes mellitus: JNC 8 recommends $<140 / 90 \mathrm{mmHg}$, while ESH/ESC 2013 recommends $140 / 85 \mathrm{mmHg}$, differing only in the diastolic target. Interestingly, the Ministry of Health Clinical Practice Guidelines on Diabetes Mellitus 2014 recommends an even lower diastolic target of $<140 / 80 \mathrm{mmHg} .{ }^{(4)}$

3. For patients with overt nephropathy: JNC 8 recommends $<140 / 90 \mathrm{mmHg}$, while ESH/ESC 2013 suggests that a "systolic $<130 \mathrm{mmHg}$ may be pursued" as long as close monitoring is done. No diastolic targets are stated.

Table I. Differences between the ESH/ESC $2013^{(3)}$ and JNC $8^{(2)}$ guidelines.

\begin{tabular}{|c|c|c|}
\hline \multirow[t]{2}{*}{ Category } & \multicolumn{2}{|l|}{ Target blood pressure (mmHg) } \\
\hline & ESH/ESC 2013 & JNC 8 \\
\hline \multicolumn{3}{|l|}{ Age (yr) } \\
\hline $18-59$ & $<140 / 90$ & $<140 / 90$ \\
\hline $60-79$ & $<140 / 90$ & $<150 / 90$ \\
\hline$\geq 80$ & $<150 / 90$ & $<150 / 90$ \\
\hline \multicolumn{3}{|c|}{ Exceptions to age-specific targets } \\
\hline Diabetes mellitus & $<140 / 85$ & $<140 / 90$ \\
\hline Overt proteinuria & Systolic $<130$ may be pursued when proteinuria is overt & $<140 / 90$ \\
\hline
\end{tabular}

I have two more comments about the case scenarios. Firstly, the ages of Mr and Mrs Wolfgang were not mentioned. This is important in deciding the appropriate blood pressure targets, and it also depends on which guideline (i.e. JNC 8 or ESC/ESH 2013) is referred to. Secondly, the blood pressures provided in the case scenarios (130-139/81-88 mmHg) are office-based readings. Home-based readings should be $<135 / 85 \mathrm{mmHg}$ on average (based on the recommendations by the ESH Workgroup on blood pressure monitoring, ${ }^{(5)}$ which is also shown in Table 6 of the ESC/ESC 2013 guidelines $\left.^{(3)}\right)$.

Yours sincerely,

lan Kwong Yun Phoon

SingHealth Polyclinics - Pasir Ris, 1 Pasir Ris Drive 4, \#01-11, Singapore 519457. phoons@singnet.com.sg

\section{RefERENCES}

1. How CH, Quah HM. PILL Series. Doctor, do I really need treatment for my current blood pressure? Singapore Med J 2014; 55:401-4.

2. James PA, Oparil S, Carter BL, et al. 2014 evidence-based guideline for the management of high blood pressure in adults: report from the panel members appointed to the Eighth Joint National Committee (JNC 8). JAMA 2014; 311:507-20.

3. Mancia G, Fagard R, Narkiewicz K, et al; Task Force Members. 2013 ESH/ESC Guidelines for the management of arterial hypertension: the Task Force for the management of arterial hypertension of the European Society of Hypertension (EHS) and of the European Society of Cardiology (ESC). J Hypertens 2013; 31:1281-357.

4. Ministry of Health, Singapore. Clinical Practice Guidelines 1/2014 Diabetes Mellitus [online]. Available at: http://www.moh.gov.sg/content/dam/moh_web/ HPP/Doctors/cpg_medical/current/2014/diabetes_mellitus/cpg_Diabetes\%20Mellitus\%20Booklet\%20-\%20Mar\%202014.pdf. Accessed August 24, 2014.

5. Parati G, Stergiou GS, Asmar R, Bilo G, de Leeuw P, Imai Y, et al. European Society of Hypertension Working Groupon Blood Pressure Monitoring. European Society of Hypertension guidelines for blood pressure monitoring at home: a summary report of the Second International Consensus Conference on Home Blood Pressure Monitoring. J Hypertens 2008; 26:1505-26. 